\title{
Rancang Bangun Sistem Informasi Akademik Fakultas Matematika Dan Ilmu Pengetahuan Alam Berbasis Website
}

\author{
Firlo Amazon $^{1)}$, Widiatry ${ }^{2 *}$, Viktor Handrianus Pranatawijaya ${ }^{3)}$ \\ 12)3) Teknik Informatika, Fakultas Teknik, Universitas Palangka Raya \\ Jalan Hendrik Timang, Kota Palangka Raya, Kalimantan Tengah, Indonesia \\ *corresponding author \\ 1) firloamazon21@gmail.com \\ ${ }^{2)}$ widiatry@it.upr.ac.id \\ ${ }^{3)}$ viktorhp@it.upr.ac.id
}

\begin{abstract}
Abstrak
Sistem informasi akademik berbasis website sangat diperlukan untuk pengolahan data akademik seperti pengolahan data mata kuliah, nilai, pengisian krs, sehingga mendukung pencapaian visi, misi dan tujuan akademik Fakultas Matematika dan Ilmu Pengetahuan Alam yang salah satunya menyelenggarakan pendidikan dengan mengoptimalkan pemanfaatan Information and Communication Technology (ICT) untuk pelayanan akademik. Dalam merancang Sistem Informasi Akademik Fakultas Matematika Dan Ilmu Pengetahuan Alam Berbasis Website ini menggunakan metode waterfall dengan tahapan, Requirements Definition, System and Software Desgin, Implementation and Unit Testing, Integration and System Testing, Operation and Maintenance. Perangkat lunak yang digunakan dalam membangun website ini adalah Visual Studio Code, MySQL, dan XAMPP. Website ini telah diuji dengan pengujian blackbox yang mengasilkan bahwa fitur dalam website dapat berjalan dengan baik. Rancang Bangun Sistem Informasi Akademik Fakultas Matematika dan Ilmu Pengetahuan Alam Berbasis Website ini dikembangkan sebagai media informasi yang memfasilitasi informasi seperti data kartu rencana studi, kartu hasil studi, dan jadwal kuliah yang dapat memfasilitasi dosen dan mahasiswa dalam mengetahui kegiatan akademik yang dilaksanakannya.
\end{abstract}

Kata kunci: Fakultas Matematika Dan Ilmu Pengetahuan Alam, Waterfall, Sistem Informasi Akademik

\begin{abstract}
A website based academic information system is indispensable for processing academic data such as processing data on subjects, grades, filling study plan cards, thus supporting the achievement of the vision, mission and academic goals of the Faculty of Mathematics and Natural Sciences, one of which is to provide education by optimizing the use of Information and Communication. Technology (ICT) for academic services. In designing the Academic Information System for the Faculty of Mathematics and Natural Sciences, this Website-Based uses the waterfall method with stages, Requirements Definition, System and Software Design, Implementation and Unit Testing, Integration and System Testing, Operation and Maintenance. The software used in building this website is Visual Studio Code, MySQL, and XAMPP. This website has been tested with blackbox testing which results that the features on the website can run well. Website-Based Design of Academic Information Systems for the Faculty of Mathematics and Natural Sciences This website was developed as an information medium that facilitates information such as study plan card data, study result cards, and class schedules that can facilitate lecturers and students in seeing the academic activities they carry out.
\end{abstract}

Keywords: Faculty of Mathematics and Natural Sciences, Waterfall, Academic Information System 


\section{PENDAHULUAN}

Pemanfaatan teknologi internet digunakan untuk memfasilitasi dalam memperoleh informasi kampus. Setiap sektor pendidikan diharapkan dapat memanfaatkan teknologi informasi sebagai penunjang kegiatan operasional dalam menghasilkan suatu informasi. Teknologi informasi adalah suatu teknologi yang digunakan untuk mengolah data, termasuk mendapatkan, menyusun, memproses, menyimpan dan memanipulasi data dalam berbagai cara untuk menghasilkan informasi yang berkualitas. Informasi yang dihasilkan harus relevan, akurat dan tepat waktu sehingga bisa digunakan untuk keperluan pribadi, pendidikan, pemerintahan, bisnis dan dimanfaatkan untuk pengambilan keputusan.

Salah satu pemanfaatan perkembangan teknologi informasi di dunia pendidikan pada perguruan tinggi negeri (PTN) yaitu dengan memanfaatkan dan mengimplementasikan sistem informasi akademik (SIA) berbasis website. Kegiatan Akademik pada Fakultas Matematika dan Ilmu Pengetahuan Alam Universitas Palangka Raya masih melakukan secara manual. Sistem pendataan yang sekarang dirasakan masih banyak kekurangan yang terjadi, dikarenakan sistem yang ada masih menggunakan lembaran kertas dan arsip sehingga menyebabkan data-data yang ada sangat mungkin hilang ataupun rusak.

\section{TINJAUAN PUSTAKA}

Beberapa penelitian yang digunakan penulis untuk menambah pemahaman dalam menganalisis dan merancang suatu aplikasi berbasis website dalam melakukan pengembangan website pengelolaan kegiatan akademik di Fakultas Matematika dan Ilmu Pengtahuan Alam UPR yaitu Rancang Bangun Website untuk Memeriksa Plagiat E-Journal Fakultas Kedokteran Universitas Palangka Raya [1], Pengembangan Aplikasi Kartu Rencana Studi Online Pada Jurusan Pendidikan Luar Sekolah Universitas Palangka Raya [2], Analisis dan Desain Website Monitoring Konsultasi Bimbingan Kartu Rencana Studi (KRS) [3], Rancang Bangun Website Sistem Informasi Pencarian Data Mahasiswa dan Dosen pada Fakultas Hukum Universitas Palangka Raya[4].

\subsection{Teori Pendukung}

\subsubsection{Sistem Informasi Akademik}

Sistem informasi akademik adalah sistem yang memberikan layanan informasi yang berupa data dalam hal yang berhubungan dengan data akademik (Setiyawan, 2013). Beberapa contoh kegiatan yang bersifat administrative di kampus adalah mengisi Kartu Rencana Studi (KRS), mengisi nilai (untuk dosen dan pegawai akademik), mengelola data dosen, mengelola data mahasiswa.

Beberapa keuntungan yang didapat dengan penerapan Sistem informasi Akademik ini adalah kemudahan bagi mahasiswa untuk memperoleh informasi tanpa harus melakukan interaksi langsung dengan bagian administrasi karena informasi tersebut dapat diperoleh dengan melakukan pencarian data melalui computer yang terkoneksi secara internet. Sistem ini juga mempermudah bagian administrasi dengan berkurangnya interaksi secara langsung yang digantikan oleh interaksi terhadap data-data yang diinputkan oleh mahasiswa yang merupakan kebutuhan untuk proses pengolahan data.

\subsubsection{Unified Modeling Language (UML)}

Unified Modeling Language adalah bahasa pemodelan visual yang digunakan untuk menspesifikasikan, memvisualisasikan, membangun dan mendokumentasikan rancangan dari suatu system perangkat lunak. Notasi UML terutama diturunkan dari 3 notasi yang telah ada sebelumnya: Grady Booch OOD (Object-Oriented Design), Jim Rumbaugh OMT (Object Modeling Technique), dan Ivar Jacobson OOSE (Object-Oriented Software Engineering). (Sri Dharwiyanti. 2013).

UML terdiri atas beberapa diagram, yaitu : Diagram Use Case, Diagram Sequence, Diagram Class.

a. Usecase Diagram 
Use case adalah sebuah unit eksternal dari sistem (berupa antar muka) yang akan menerima perintah dari seorang aktor berupa sebuah event. Use case ini terkait dengan implementasi didalamnya yang berupa urutan-urutan penyampaian pesan-pesan antar objek-objek yang berkaitan [5].

b. Sequence Diagram

Sequence diagram menggambarkan tingkah laku dari satu scenario tunggal. Diagram ini menunjukkan objek-objek yang terlibat dalam proses tersebut dan bagaimana urutan penyampaian pesan-pesan antara objek-objek tersebut [5].

c. Class Diagram

Class Diagram adalah diagram yang menunjukkan satu set kelas-kelas, antarmukaantarmuka dan hubungan-hubungannya [5].

\subsubsection{Framework Codeigniter}

Framework adalah kumpulan instruksi-instruksi yang dikumpulkan dalam class dan function-function dengan fungsi masing-masing untuk memudahkan developer/programmer dalam pemanggilannya tanpa harus menuliskan syntax program yang sama secara berulang-ulang. Hal ini memiliki kegunaan untuk menghemat waktu dan mencegah penulisan syntax secara berulang-ulang agar terciptanya source code (kode program) yang bersih dan terstruktur [6].

\section{METODE PENELITIAN}

Metodologi penelitian yang dilakukan menggunakan terbagi atas dua metode yaitu metode pelaksanaan dan metode pengembangan perangkat lunak.

\subsection{Metode Pelaksanaan}

Adapun metode yang digunakan dalam menyelesaikan pembuatan Website Sistem Informasi Akademik Fakultas Matematika dan Ilmu Pengetahuan Alam, yaitu;

a. Metode Pengumpulan Data

Tahap pengambilan data yang berkaitan dengan permasalahan yang di bahas. Metode ini menggunakan teknik observasi, yakni pengamatan langsung terhadap Fakultas Matematika dan Ilmu Pengetahuan Alam yang akan di teliti.

b. Metode Studi Kepustakaan

Studi Kepustakaan antara lain seperti mempelajari informasi dari internet yang memiliki kaitan dengan proses pembuatan website Sistem Informasi Akademik dan memilah kembali fitur-fitur apa saja yang cocok untuk diterapkan dalam website.

c. Metode Konsultasi

Metode konsultasi merupakan proses tanya jawab atau bimbingan dan diskusi kepada dosen pembimbing mengenai website yang di buat sehingga ditemukan arah seperti apa website nantinya.

d. Metode Implementasi

Metode ini di mana mulai melakukan proses pengerjaan website dengan data yang sudah dikumpulkan dan dirancang sedemikian rupa.

\subsection{Metode Pengembangan Perangkat Lunak}

Metode yang digunakan dalam pembuatan website ini adalah metode waterfall, metode ini pertama kali dikenalkan oleh Winston Royce pada tahun 1970, metode ini dipilih karena mempunyai struktur yang lebih terarah baik itu dalam setiap perancangan maupun implementasinya sehingga dengan berbagai pertimbangan kualitas sistem yang dihasilkan akan lebih baik [7]. Rancangan penelitian yang dibuat terdiri atas dua tahap yaitu: (1) pengumpulan dan analisis data yang dilakukan dengan cara studi Pustaka dan observasi, (2) menerapkan metode waterfall [8] yang sudah dimodifikasi dengan tahapa-tahapnya adalah analisis sistem, desain, implementasi dan pengujian. Selanjutnya pada tahapan testing menggunakan metode Blackbox [9] [10] [11].

Dibawah ini pada gambar 1 merupakan metode waterfall yang digunakan: 


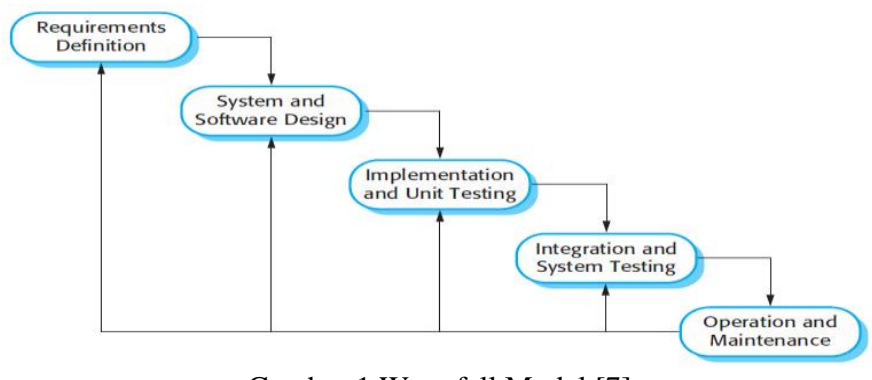

Gambar 1 Waterfall Model [7]

\section{PEMBAHASAN}

\subsection{Perancangan Sistem}

a. Use Case Diagram

1. Dibawah ini pada gambar 2 merupakan Use Case Diagram Actor Admin:

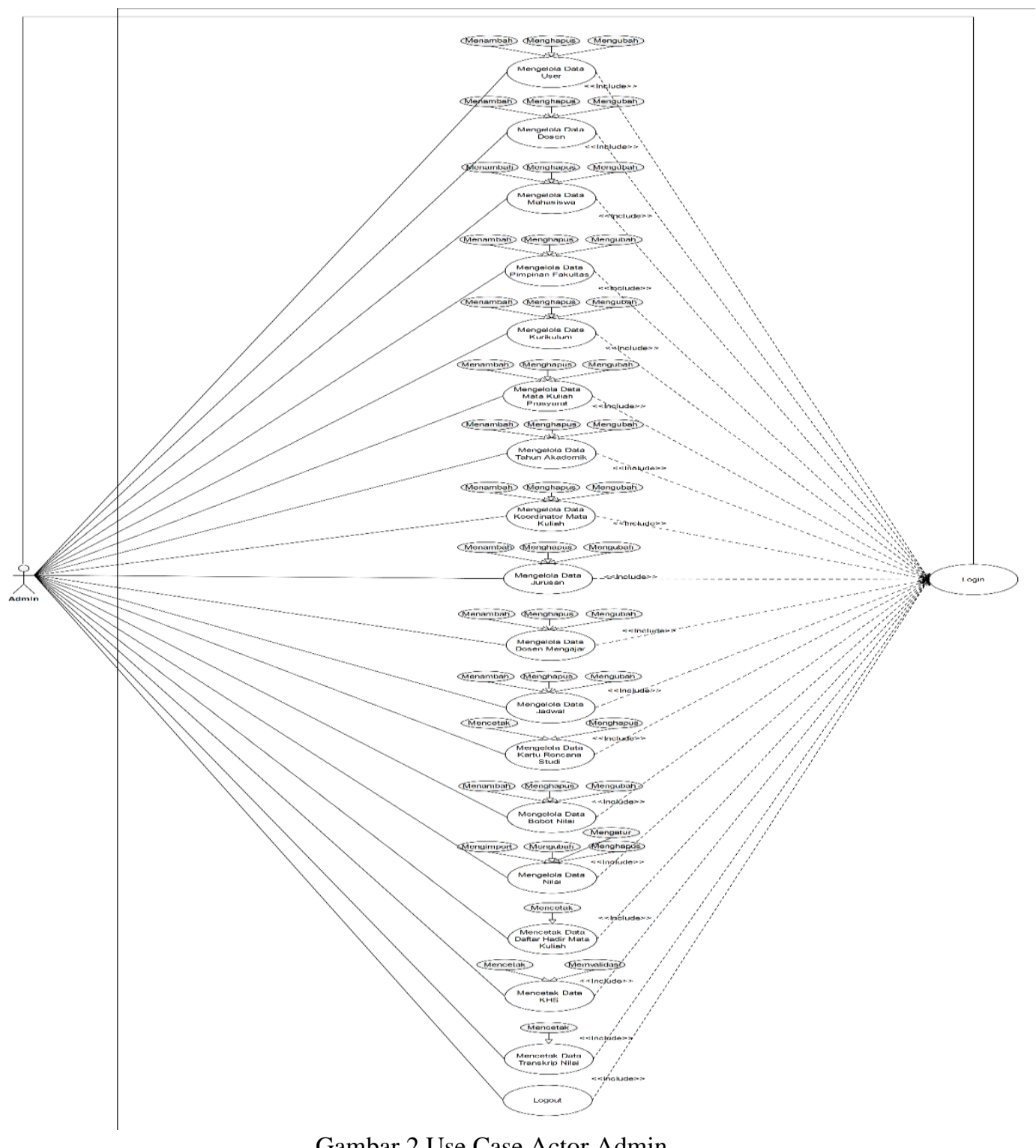

Gambar 2 Use Case Actor Admin

2. Dibawah ini pada gambar 3 merupakan Use Case Diagram Actor Dosen: 


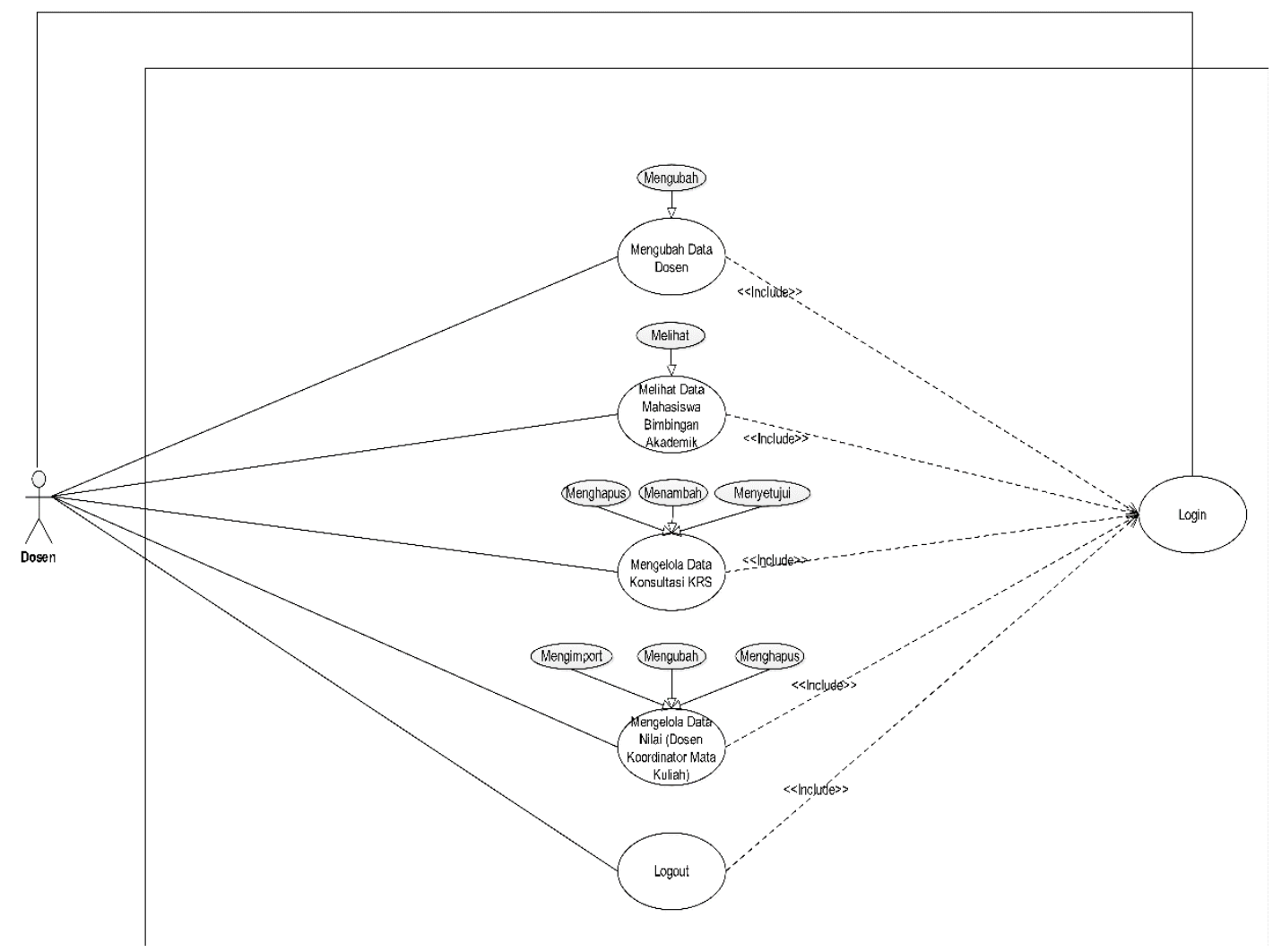

Gambar 3 Use Case Actor Admin

3. Dibawah ini pada gambar 4 merupakan Use Case Diagram Actor Mahasiswa:

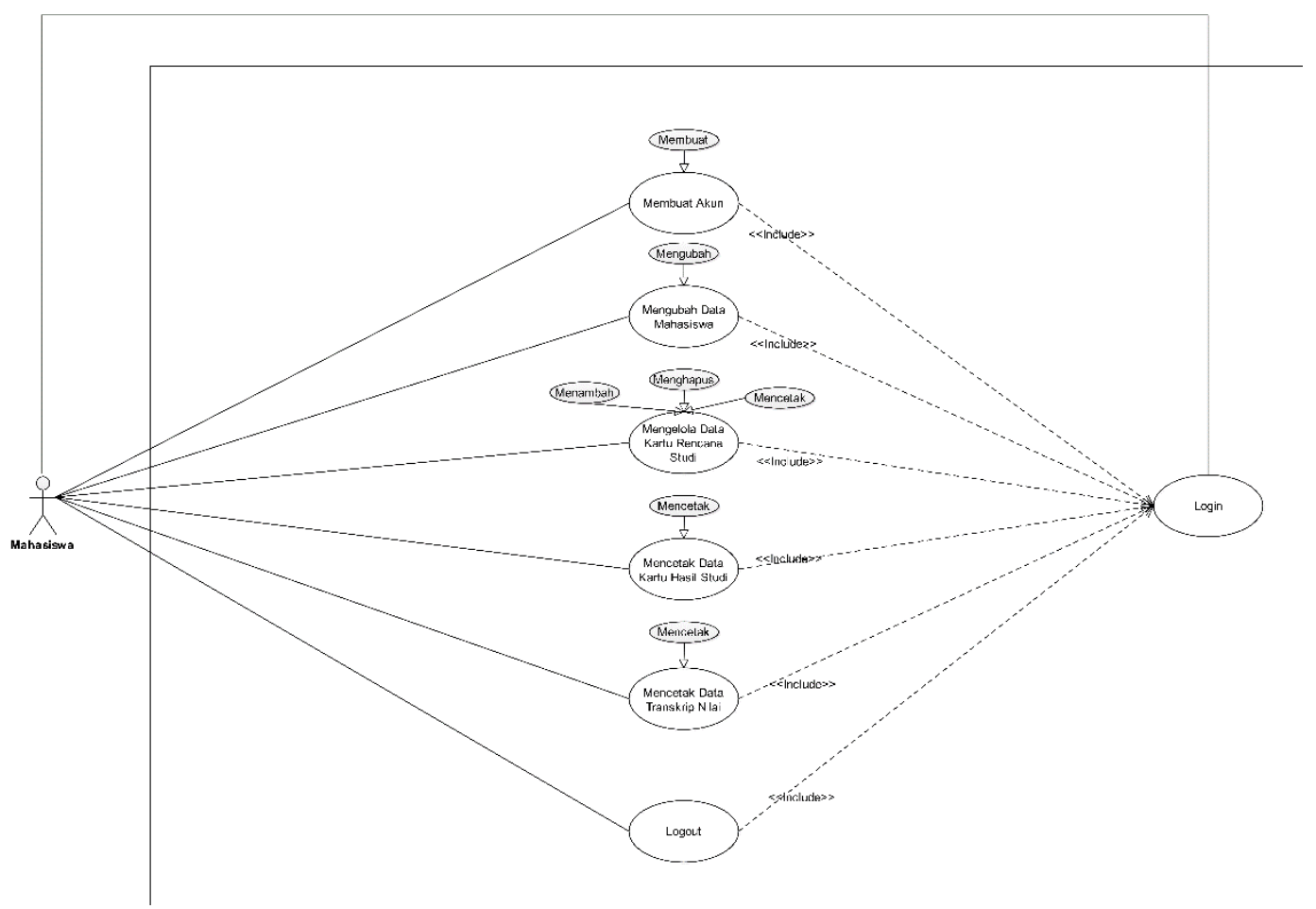

Gambar 4 Use Case Actor Mahasiswa 
b. Class Diagram

Dibawah ini pada gambar 5 merupakan Class Diagram :

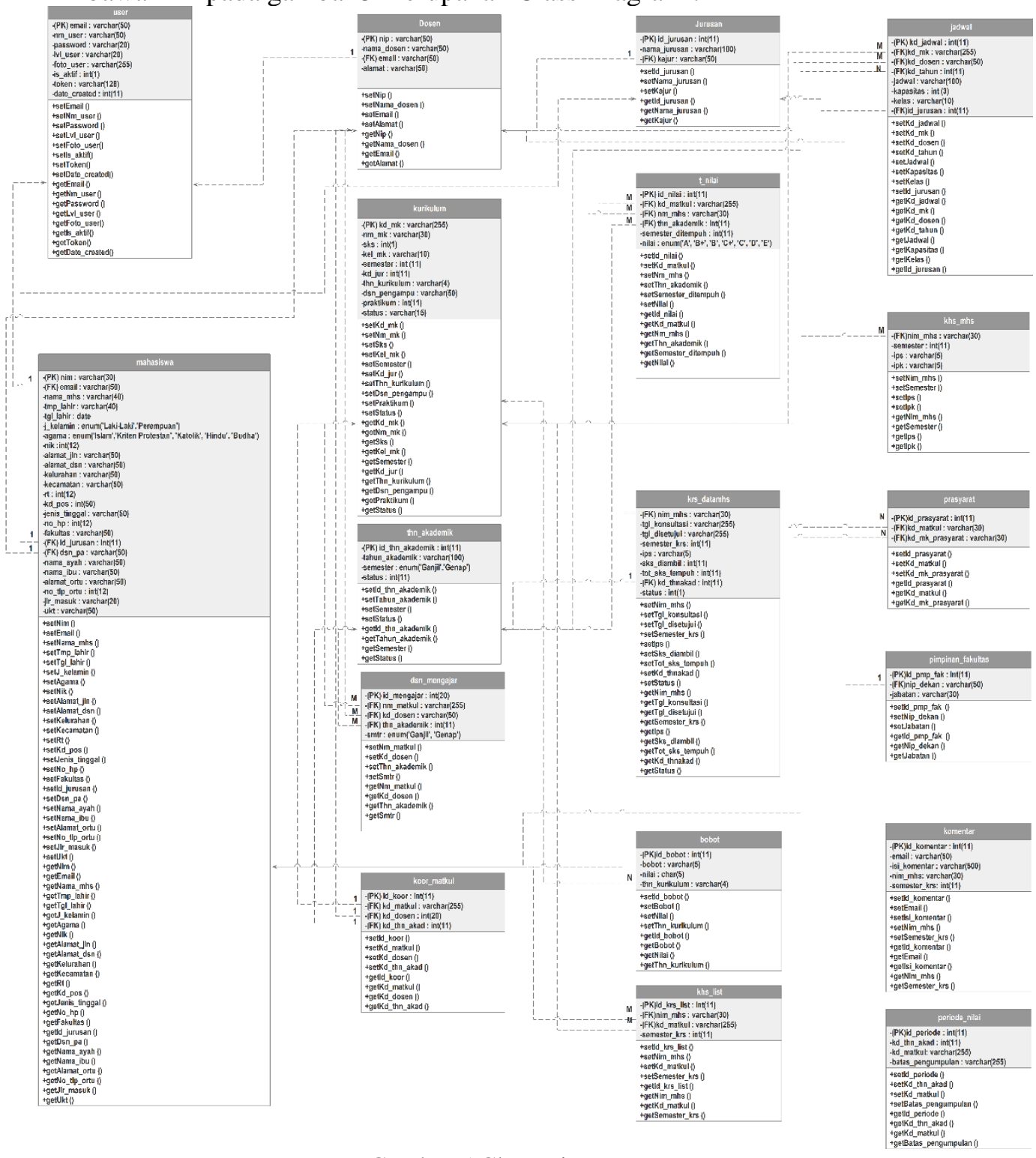

Gambar 5 Class Diagram

c. Sequence Diagram

1. Dibawah ini pada gambar 6 merupakan Sequence Diagram Tambah Data Dosen Actor Admin :

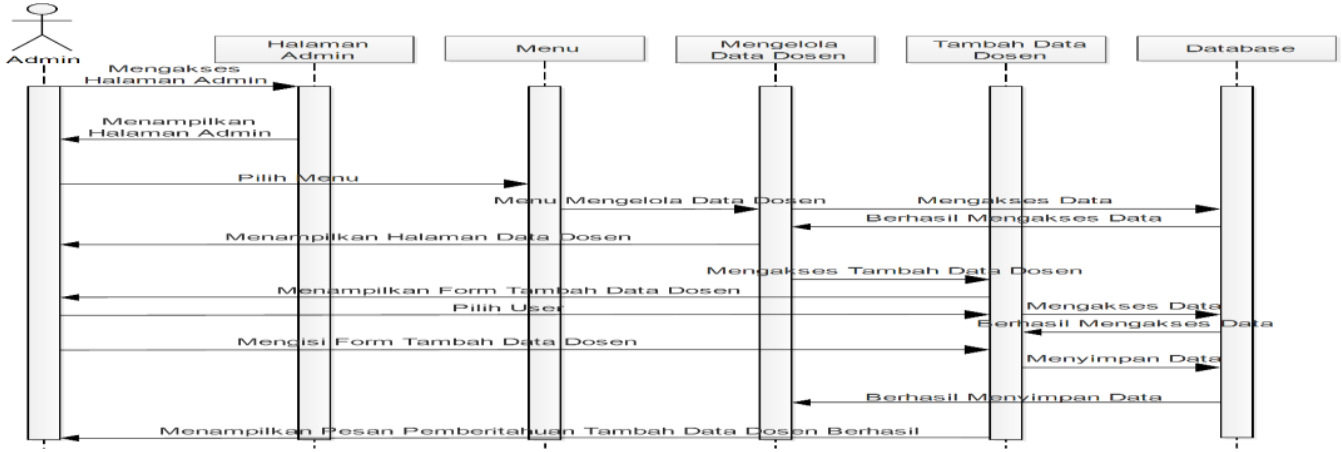

Gambar 6 Sequence Diagram Tambah Data Dosen Actor Admin 
2. Gambar 7 merupakan Sequence Diagram Menyetujui Data Konsultasi Kartu Rencana Studi Actor Dosen.

3. Gambar 8 merupakan Sequence Diagram Tambah Data Kartu Rencana Studi Actor Mahasiswa.

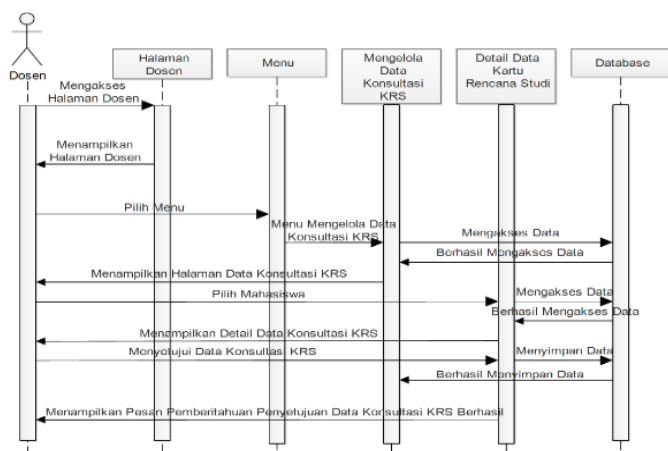

Gambar 7 Sequence Diagram Menyetujui Data Konsultasi Kartu Rencana Studi Actor Dosen

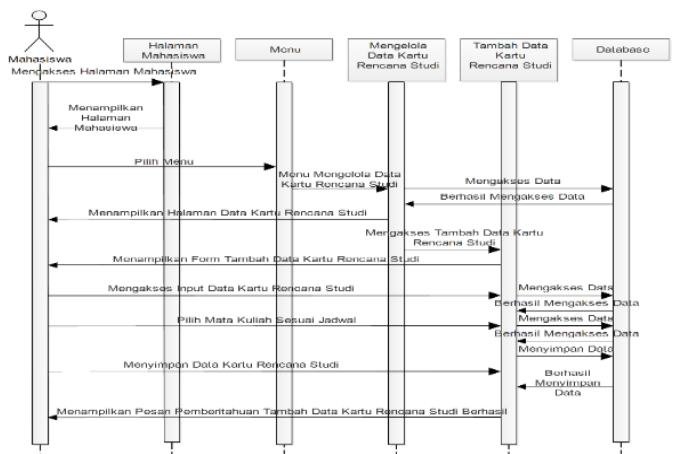

Gambar 8 Sequence Diagram Tambah Data Kartu Rencana Studi Actor Mahasiswa

\subsection{Perancangan Desain Sistem}

a. Gambar 9 menunjukkan desain Halaman Login.

b. Gambar 10 menunjukkan desain Halaman Dashboard Admin.

c. Gambar 11 menunjukkan desain Halaman Dashboard Dosen.

d. Gambar 12 menunjukkan desain Halaman Dashboard Mahasiswa.
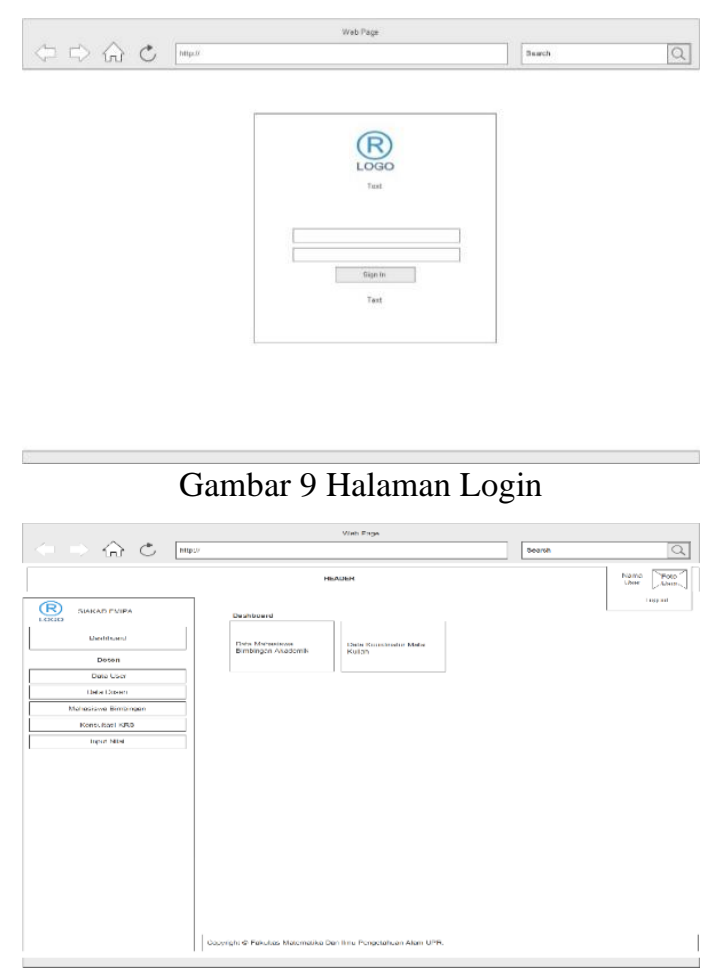

Gambar 11 Halaman Dashboard Dosen

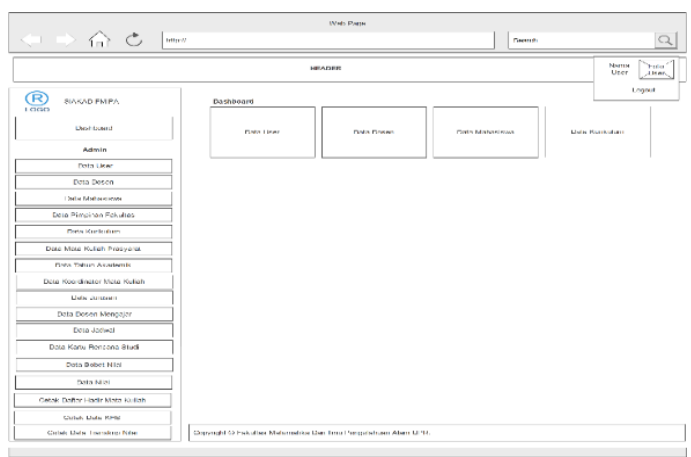

Gambar 10 Halaman Dashboard Admin

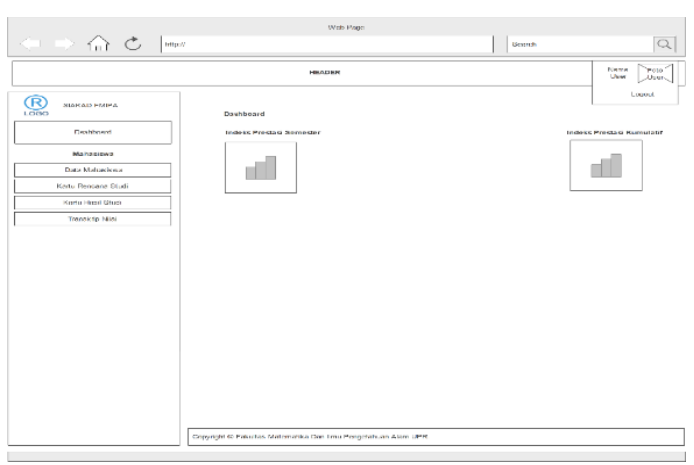

Gambar 12 Halaman Dashboard Mahasiswa 


\subsection{Hasil Tampilan Sistem}

a. Gambar 13 menunjukkan halaman login admin, dosen, dan mahasiswa.

b. Gambar 14 menunjukkan halaman dashboard admin.

c. Gambar 15 menunjukkan halaman dashboard dosen.

d. Gambar 16 menunjukkan halaman dashboard mahasiswa.

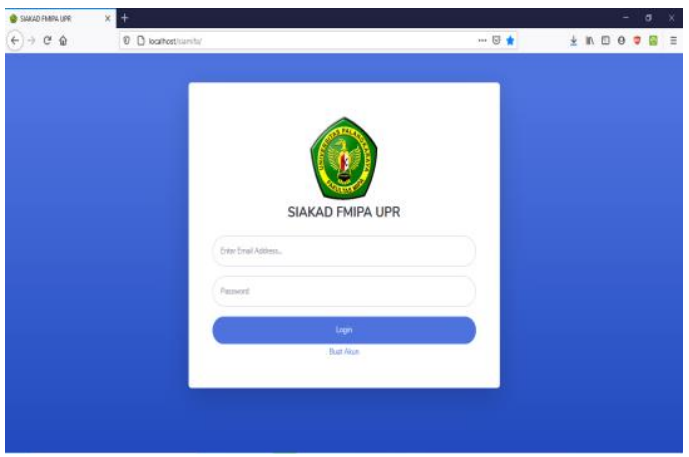

Gambar 13 Halaman Login

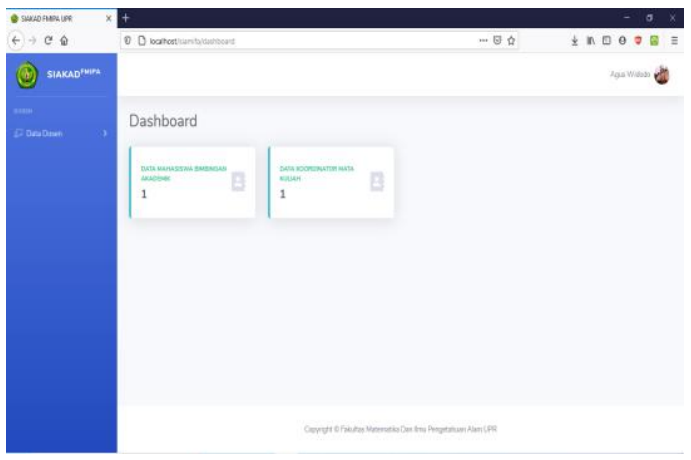

Gambar 15 Halaman Dashboard Dosen

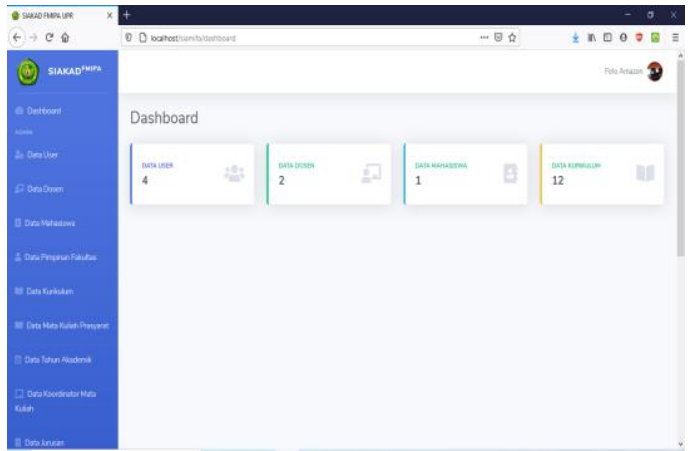

Gambar 14 Halaman Dashboard Admin

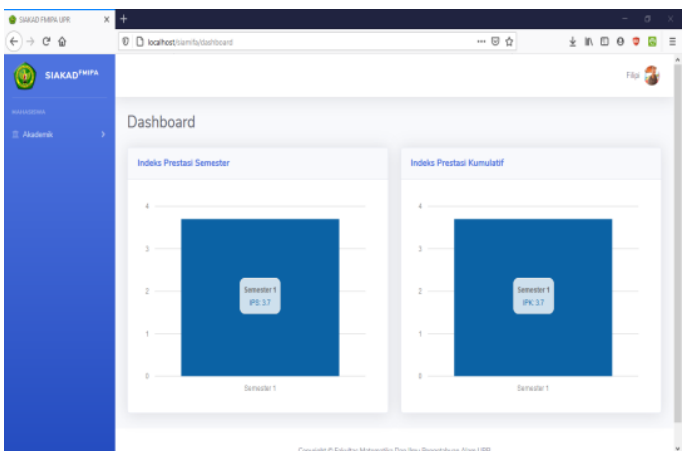

Gambar 16 Halaman Dashboard Mahasiswa

\section{KESIMPULAN}

Dalam merancang dan membangun website ini menggunakan metodologi pengembangan perangkat lunak Waterfall Menurut Summerville tahun 2011, yang memiliki tahapan yaitu requirements definition yang dilakukan dalam pembuatan perancangan bisnis proses dan flowchart. System and software design dilakukan dalam pembuatan Use Case, Sequential Diagram dan Class Diagram, dan desain interface. Implementation and unit system dengan bahasa pemrograman yang digunakan yaitu HTML, PHP, CSS, Bootstrap, Javascript, Framework Codeigniter 3.0 dan MySQL dan. Integration and system testing metode testing yang digunakan pada pembuatan Web ini adalah metode Blackbox. Dari hasil pengujian ini dapat disimpulkan bahwa Website ini dapat berjalan sesuai dengan fungsi.

Adanya website Sistem Informasi Akademik Fakultas Matematika dan Ilmu Pengetahuan Alam ini akan memfasilitasi admin, dosen dan mahasiswa dalam mengetahui kegiatan akademik yang dilaksanakan.

\section{DAFTAR PUSTAKA}

[1] Widiatry, W. \& Sari, N. N. K., (2019). Rancang Bangun Website untuk Memeriksa Plagiat E-Journal Fakultas Kedokteran Universitas Palangka Raya. Jurnal CoreIT 5(2), 36-43.

[2] Widiatry, W. (2020). PENGEMBANGAN APLIKASI KARTU RENCANA STUDI ONLINE PADA JURUSAN PENDIDIKAN LUAR SEKOLAH UNIVERSITAS PALANGKA RAYA. JURNAL TEKNOLOGI INFORMASI, 14(1), 83-93. 
[3] Putra, P. B. A. A., Sari, N. N. K., \& Pranatawijaya, V. H. (2017). Analisis Dan Desain Website Monitoring Konsultasi Bimbingan Kartu Rencana Studi (KRS). Jurnal Teknologi Informasi, 11(1).

[4] Putra, P. B. A. A., Pranatawijaya, V. H., Widiatry, W., \& Lisa, L. (2017). Rancang Bangun Sistem Informasi Pencarian Data Mahasiswa dan Dosen pada Fakultas Hukum Universitas Palangka Raya.Jurnal Teknologi Informasi,11(2).

[5] Akil. Ibnu, Referensi dan Panduan UML 2.4 Singkat Tepan dan Jelas. Surabaya: CV. Garuda Mas Sejahtera, 2018.

[6] Alfarabi Hadi. Diki, "Codeigniter Part 1 : Pengertian dan Cara Menggunakan CodeIgniter," 2019. [Online]. Tersedia : https://www.malasngoding.com/pengertian-dancara-menggunakan-codeigniter/. [diakses pada 22 Februari 2020]

[7] Royce, Winston. (1970). Managing the Development of Large Software Systems, Proceedings of IEEE WESCON 26 (August):1-9.

[8] Pressman, S. Roger. (2010). Pendekatan Praktisi Rekayasa Perangkat Lunak. Edisi 7. Penerbit Andi. Yogyakarta. Halaman 45-46.

[9] Widiatry, W., Sari, N. N. K., Pranatawijaya, V. H., \& Putra, P. B. A. A. (2019). Penerapan Algoritma Levenshtein Distance Untuk Pencarian Pada Sistem Informasi Perpustakaan Fakultas Kedokteran Universitas Palangka Raya. Jurnal SAINTEKOM, 9(1), 66-82.

[10] Putra, P. B. A. A., Pranatawijaya, V. H., Widiatry, W., \& Sari, N. N. K., (2019). Pengembangan Perangkat Lunak Generate File Data Kehadiran Pegawai Universitas Palangka Raya. Anterior Jurnal,18(2), 182-189.

[11] Putra, P. B. A. A., Pranatawijaya, V. H., Widiatry, W., \& Natalius, N. (2018). Analisis dan Desain Perangkat Lunak Generate File Akun Uang Kuliah Tunggal (UKT) Universitas Palangka Raya. JURNAL TEKNOLOGI INFORMASI, 12(1), 42-49. 